\title{
Intraosseous versus intravenous access while wearing personal protective equipment: a meta-analysis in the era of COVID-19
}

\author{
Anna Drozd ${ }^{1}$, Jacek Smereka1,2, Krzysztof J. Filipiak' ${ }^{3}$, Miłosz Jaguszewski ${ }^{4}$, Jerzy R. Ładny ${ }^{1,5}$, \\ Karol Bielski', Klaudiusz Nadolny ${ }^{5,6,7}$, Kurt Ruetzler ${ }^{8}$, Łukasz Szarpak ${ }^{1,9,10}$ \\ 1 Polish Society of Disaster Medicine, Warsaw, Poland \\ 2 Department of Emergency Medical Service, Wroclaw Medical University, Wrocław, Poland \\ 3 1st Chair and Department of Cardiology, Medical University of Warsaw, Warsaw, Poland \\ 4 1st Department of Cardiology, Medical University of Gdansk, Gdańsk, Poland \\ 5 Clinic of Emergency Medicine, Medical University of Bialystok, Białystok, Poland \\ 6 Department of Emergency Medical Service, Higher School of Strategic Planning in Dabrowa Gornicza, Dąbrowa Górnicza, Poland \\ 7 Faculty of Medicine, Katowice School of Technology, Katowice, Poland \\ 8 Departments of Outcomes Research and General Anesthesia, Anesthesiology Institute, Cleveland Clinic, Cleveland, Ohio, United States \\ 9 Bialystok Oncology Center, Białystok, Poland \\ 10 Maria Skłodowska-Curie Medical Academy in Warsaw, Warsaw, Poland
}

\section{KEY WORDS}

COVID-19,

intravascular access, intraosseous,

intravenous,

meta-analysis

\section{EDITORIAL}

by Paganini, Dalla

Vecchia, and Franco,

see p. 246

\section{ABSTRACT}

BACKGROUND Obtaining vascular access is one of the key procedures performed in patients in emergency settings.

AIMS The study was conducted as a meta-analysis and a systematic review and aimed to address the following question: which intravascular access method should be used in patients with COVID-19 when wearing full personal protective equipment (PPE)?

METHODS We performed a systematic search of PubMed, EMBASE, and CENTRAL databases for randomized controlled trials that compared intravascular access methods used by operators wearing full level C PPE. We evaluated procedure duration and the success rate of intraosseous and peripheral intravenous accesses. RESULTS Eight randomized controlled trials were included in quantitative synthesis. The use of PPE during intravascular access procedures had an impact on procedure duration in the case of intraosseous access (mean difference [MD], 11.69; 95\% CI, 6.47-16.92; $P<0.001$ ), as well as reduced the success rate of intraosseous access by $0.8 \%$ and intravenous access by $10.1 \%$. Under PPE conditions, intraosseous access, compared with peripheral intravenous access, offered a shorter procedure time (MD, -41.43 ; $95 \%$ CI, -62.36 to $-24.47 ; P<0.001)$.

CONCLUSION This comprehensive meta-analysis suggested that the use of PPE significantly extends the duration of intravascular procedures. However, under PPE conditions, operators were able to obtain intraosseous access in a shorter time and with a higher success rate than in the case of intravenous access.

INTRODUCTION Obtaining vascular access is one of the key components of critical care medicine including out-of-hospital emergency medicine and rescue operations. Vascular access enables the administration of drugs and infusions, including those used in sudden cardiac arrest, as well as catecholamines in various types of shock. The time to establish vascular access is crucial in emergency medicine, especially for critically ill patients. In numerous clinical situations, it is a major challenge for medical personnel, especially those with less experience. 'Vascular access can be achieved either through peripheral or central venous access, or through intraosseous access. Intraosseous access was initially used mainly in pediatric patients, but it is now increasingly applied in adult patients as well. ${ }^{2,3}$ 


\section{WHAT'S NEW?}

This is the first meta-analysis to evaluate the effectiveness of intravascular access in personal protective equipment-restricted scenarios. The study was designed as a meta-analysis and a systematic review and aimed to determine which intravascular access method should be preferred when wearing full personal protective equipment to care for high-risk, infectious or contaminated patients, such as those with suspected or confirmed COVID-19.

SARS-CoV-2 is transmitted via the droplet route. Because of its relatively high infectivity and the need for long-term testing to confirm or rule out the infection, as well as the necessity of quarantining people who have had contact with an infected person, including medical personnel, the virus poses a serious risk to the functioning of healthcare systems. ${ }^{4,5}$

Although more than $80 \%$ of patients with COVID-19 have mild symptoms, some even being asymptomatic, about $5 \%$ to $15 \%$ of cases are severe. Some patients develop cytokine storm and consequently ARDS and multiorgan failure, which is the cause of death in a high percentage of critically ill patients with COVID-19. ${ }^{6}$ The use of protective masks by medical personnel, including primarily masks with a suitable filter, and also of protective clothing and double gloves is essential. ${ }^{7}$ According to the United States Centers for Disease Control and Prevention, medical personnel who interact with patients with known or suspected COVID-19 should adhere to standard precautions and use a respirator (or a facemask if a respirator is not available), a gown, gloves and eye protection. Some procedures, such as endotracheal intubation or bronchoscopy, could generate infectious aerosols. Consequently, medical personnel should wear an N95 or higher-level respirator such as disposable filtering facepiece respirators.

Numerous studies have compared the time of obtaining and the effectiveness of intravenous and intraosseous access. ${ }^{8,9}$ The current SARS- CoV-2 pandemic forces medical personnel to use personal protective equipment (PPE) including double gloves, goggles, masks with appropriate filters, visors, and protective clothing. Such safety measures are particularly important in emergency medicine when the team is dispatched to a patient with suspected or confirmed COVID-19. Medical personnel may need to initiate emergency procedures, including vascular access. Personal protective equipment makes it difficult to carry out emergency procedures, among others, to obtain vascular access. It is reasonable to compare studies on the efficacy and timing of vascular access placement with different methods when using PPE, especially level $C$ protection..$^{10}$

This is the first meta-analysis to evaluate the effectiveness of intravascular access in PPE-restricted scenarios. The study was conducted as a meta-analysis and a systematic review. It aimed to answer the following question: which intravascular access method should be used when wearing full PPE to care for high-risk, infectious, or contaminated patients, such as those with suspected or confirmed COVID-19?

METHODS We conducted a systematic review of randomized controlled trials (RCTs) in accordance with the Cochrane Collaboration guidance. The presented review followed the Preferred Reporting Items for Systematic Reviews and Meta-Analyses (PRISMA) statement ${ }^{11}$ (Supplementary material). For this meta-analysis, neither ethics committee approval nor patient consent were required.

Eligibility criteria Studies were included if they met the following criteria: 1) RCT; 2) clinical, cadaver, or simulation trial; 3) provided data on intravascular access of in adult patient or a simulator; 4) compared intravascular access performed with and without level C PPE; and 5) reported procedure duration or success rates. Review articles and case studies were excluded. No language restrictions were placed on the search results.

Search strategy A comprehensive literature search was performed with PubMed, Scopus, EMBASE, Web of Science, and Cochrane Central Register of Controlled Trials (CENTRAL) databases, from the inception of each database up to April 10, 2020. The following terms were used: "intravascular" or "intravenous" or "intraosseous" or "iv" or "io" or "EZ-IO" or "B.I.G." or "NIO" or "FAST 1" or "Jamshidi" or "Cook" and "PPE" or "personal protective equipment" or "HazMat" or "Level C protective" or "CBRN" or "Chemical" or "toxic" or "infectious patient." The electronic database search was supplemented by searching Google Scholar and by back-searching the reference lists of the identified studies for suitable articles.

Study selection The references retrieved by electronic search were imported to and managed by the EndNote X7 software (Clarivate). Two independent investigators (JS and KL) screened both titles and abstracts to exclude inconsistent studies. Discrepancies were resolved by a third author (MJ). Relevant full-text articles were retrieved and analyzed for eligibility using the predefined inclusion criteria.

Data extraction Raw data were extracted using a standardized, premade form. Two authors (KL and JS) independently assessed each article to determine whether or not it met the criteria for inclusion. Disagreements between the authors regarding values or analysis assignments were resolved through discussion with a third researcher (LS), and the decision was taken by the majority of the researchers. The agreement with respect to study inclusion was assessed by using the Cohen 
TABLE 1 Comparison of intraosseous access times with and without personal protective equipment

\begin{tabular}{llllll} 
Variable & & Trials, $\mathbf{n}$ & MD or RR $(95 \%$ CI $)$ & P value & $I^{2}$ statistics, \% \\
\cline { 2 - 6 } Operator specialty & Physicians & 1 & $10(8.42-11.58)$ & $<0.001$ & N/A \\
\cline { 2 - 6 } & Paramedics & 3 & $11.46(3.62-19.31)$ & 0.004 & 94 \\
\cline { 2 - 6 } & Mixed staff & 4 & $15.44(11.13-19.75)$ & $<0.001$ & 47 \\
\hline $\begin{array}{l}\text { Intraosseous access } \\
\text { device type }\end{array}$ & EZ-IO & 6 & $11.32(3.84-18.79)$ & 0.003 & 97 \\
\cline { 2 - 6 } & BIG & 2 & $9.78(8.27-11.29)$ & $<0.001$ & 0 \\
\cline { 2 - 6 } & Jamshidi & 1 & $34.5(23.62-45.38)$ & $<0.001$ & $\mathrm{NA}$ \\
\hline
\end{tabular}

Abbreviations: BIG, bone injection gun; MD, mean difference; NA, not applicable; RR, risk ratio

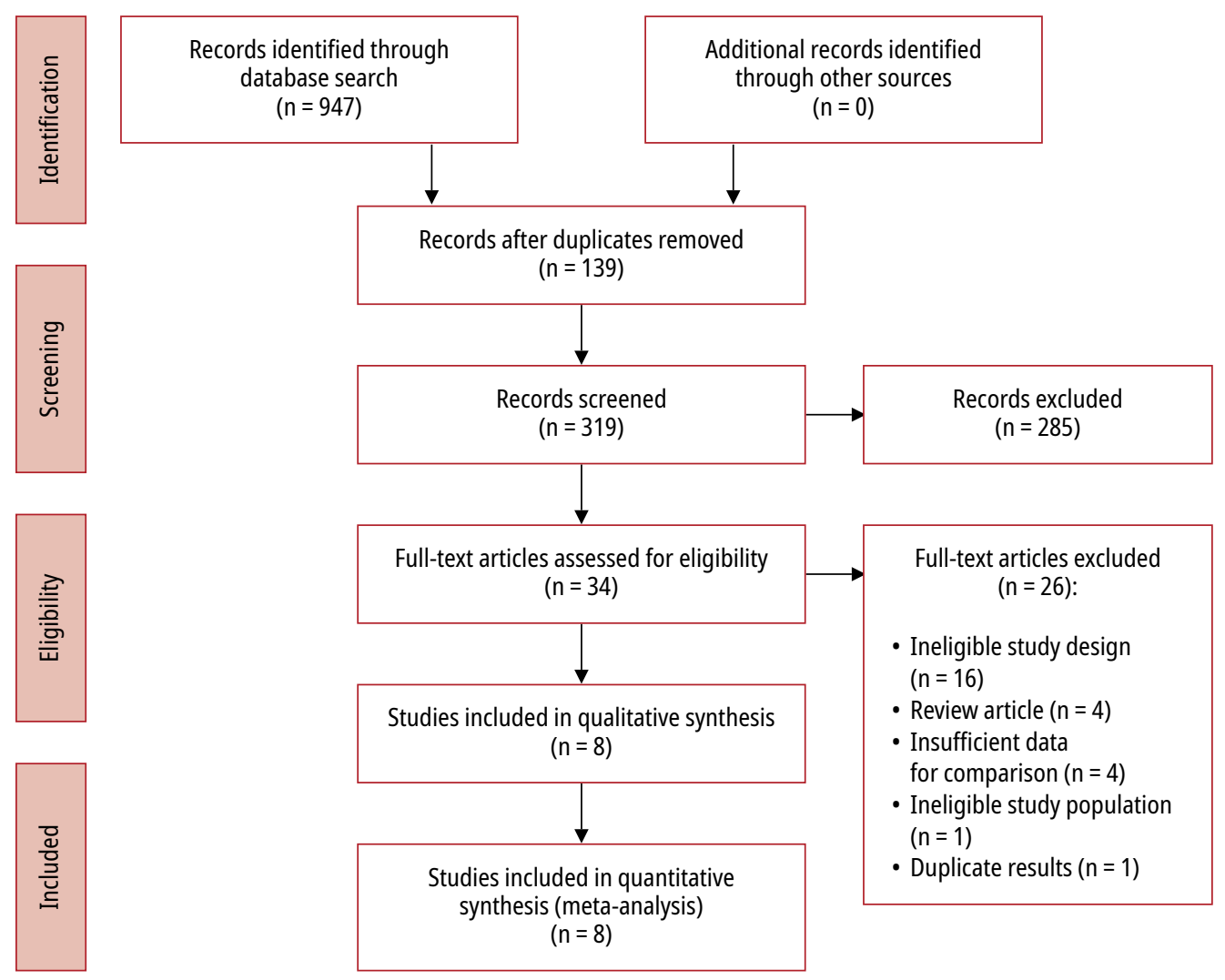

FIGURE 1 Flow diagram showing the stages of database search and study selection as per the PRISMA guidelines. Modified from Moher et al11

к statistics. ${ }^{12}$ We were careful to avoid inclusion of data from duplicate publications. In any case of suspected data discrepancies, we contacted the relevant author directly. Data extracted from eligible studies included the following characteristics: study and year, country, participants, number of participants, types of devices applied for intravascular access, procedure with or without PPE, procedure duration (measured in seconds), and success of intravascular access.

Statistical analysis Individual study data for intravascular access success rates and procedure duration were analyzed. We used MantelHaenszel models for all dichotomous outcomes and the inverse variance method for continuous outcomes. For continuous variables (procedure duration), mean differences (MD) were calculated. A random effect model was applied to analyze the data. Results are presented as risk ratios (RRs) with 95\% CIs for dichotomous variables. The meta-analysis was carried out with the Review Manager (RevMan) software for Mac; version 5.3 (Cochrane Collaboration, Oxford, United Kingdom). When the continuous variable was reported in a study as median, range, and interquartile range, we estimated means and SDs using the formula described by Hozo et al. ${ }^{13}$ We quantified heterogeneity in each analysis using the $T^{2}$ and $I^{2}$ statistics. Studies were subgrouped 
TABLE 2 Characteristics of the included studies

\begin{tabular}{|c|c|c|c|c|c|c|c|c|c|}
\hline Study & Patients, n & $\begin{array}{l}\text { Study } \\
\text { design }\end{array}$ & $\begin{array}{l}\text { PPE } \\
\text { level }\end{array}$ & $\begin{array}{l}\text { Study } \\
\text { object }\end{array}$ & $\begin{array}{l}\text { Study } \\
\text { device }\end{array}$ & $\begin{array}{l}\text { Procedural } \\
\text { conditions }\end{array}$ & Operators & $\begin{array}{l}\text { Definition of } \\
\text { injection time }\end{array}$ & $\begin{array}{l}\text { Injection } \\
\text { success rate }\end{array}$ \\
\hline $\begin{array}{l}\text { Ben- } \\
\text {-Abraham } \\
\text { et al }{ }^{19}\end{array}$ & 20 & RCT & C & $\begin{array}{l}\text { Turkey } \\
\text { femurs }\end{array}$ & BIG & $\begin{array}{l}\text { With and } \\
\text { without PPE }\end{array}$ & $\begin{array}{l}\text { Emergency care } \\
\text { physicians previously } \\
\text { inexperienced with } \\
\text { BIG }\end{array}$ & $\begin{array}{l}\text { From the moment } \\
\text { the BIG was } \\
\text { attached to } \\
\text { the bone until } \\
\text { the successful } \\
\text { placement of } \\
\text { the needle was } \\
\text { achieved }\end{array}$ & $\begin{array}{l}\text { A bare } \\
\text { needle } \\
\text { anchored in } \\
\text { a firm } \\
\text { upright } \\
\text { position in } \\
\text { the bone }\end{array}$ \\
\hline $\begin{array}{l}\text { Borron } \\
\text { et al }{ }^{14}\end{array}$ & 16 & RCT & $\begin{array}{l}A, B, C \text {, } \\
\text { and D }\end{array}$ & Goats & EZ-IO & $\begin{array}{l}\text { With and } \\
\text { without PPE }\end{array}$ & $\begin{array}{l}12 \text { ED physicians, } \\
\text { physician assistants, } \\
\text { and nurses }\end{array}$ & $\begin{array}{l}\text { From the moment } \\
\text { participants } \\
\text { touched either } \\
\text { the EZ-IO needle } \\
\text { cover or the driver } \\
\text { throughout } \\
\text { needle placement } \\
\text { and bone marrow } \\
\text { aspiration (where } \\
\text { possible) and until } \\
\text { they completed } \\
\text { the injection of } \\
\text { a } 5 \text {-ml bolus of } \\
\text { isotonic sodium } \\
\text { chloride solution }\end{array}$ & $\begin{array}{l}\text { Noted by } \\
\text { aspiration of } \\
\text { bone } \\
\text { marrow } \\
\text { and/or } \\
\text { facile } \\
\text { injection of } \\
5 \mathrm{ml} \mathrm{of} \\
\text { isotonic } \\
\text { sodium } \\
\text { chloride } \\
\text { solution }\end{array}$ \\
\hline $\begin{array}{l}\text { Castle } \\
\text { et al }{ }^{8}\end{array}$ & 64 & RCT & C & Manikin & $\begin{array}{l}\text { IV and } \\
\text { EZ-IO }\end{array}$ & $\begin{array}{l}\text { With and } \\
\text { without PPE }\end{array}$ & $\begin{array}{l}4 \text { prehospital care } \\
\text { doctors (ALS-trained } \\
\text { general practitioners } \\
\text { activated by } \\
\text { the ambulance } \\
\text { service), } 6 \\
\text { resuscitation officers, } \\
14 \text { paramedics, } 15 \\
\text { anesthetists, and } 25 \\
\text { emergency } \\
\text { physicians }\end{array}$ & $\begin{array}{l}\text { From when } \\
\text { the EZ-IO drill was } \\
\text { picked up until } \\
\text { the IO needle was } \\
\text { placed into } \\
\text { a training bone } \\
\text { and a 3-way } \\
\text { extension } \\
\text { attached }\end{array}$ & Not specified \\
\hline Collins ${ }^{15}$ & 8 & RCT CP & C & Cadaver & EZ-IO & $\begin{array}{l}\text { With and } \\
\text { without PPE }\end{array}$ & Paramedics & Not specified & Not specified \\
\hline $\begin{array}{l}\text { Lamhaut } \\
\text { et al }{ }^{16}\end{array}$ & 25 & RCT & C & Manikin & $\begin{array}{l}\text { IV and } \\
\text { EZ-IO }\end{array}$ & $\begin{array}{l}\text { With and } \\
\text { without PPE }\end{array}$ & $\begin{array}{l}9 \text { nurses and } 16 \\
\text { physicians }\end{array}$ & $\begin{array}{l}\text { From the moment } \\
\text { the device was } \\
\text { attached to } \\
\text { the bone until } \\
\text { the successful } \\
\text { placement of } \\
\text { the needle was } \\
\text { achieved }\end{array}$ & $\begin{array}{l}\text { Successful } \\
\text { fluid infusion }\end{array}$ \\
\hline $\begin{array}{l}\text { Suyama } \\
\text { et a }\left.\right|^{17}\end{array}$ & 22 & RCT & C & Manikin & $\begin{array}{l}\text { IV and } \\
\text { EZ-IO }\end{array}$ & $\begin{array}{l}\text { With and } \\
\text { without PPE }\end{array}$ & Paramedics & Not specified & Not specified \\
\hline $\begin{array}{l}\text { Szarpak } \\
\text { et al }{ }^{18}\end{array}$ & 40 & RCT & C & Manikin & $\begin{array}{l}\text { BIG and } \\
\text { Jamshidi }\end{array}$ & $\begin{array}{l}\text { With and } \\
\text { without PPE }\end{array}$ & Paramedics & $\begin{array}{l}\text { From the moment } \\
\text { the device was } \\
\text { touched to } \\
\text { successful fluid } \\
\text { infusion }\end{array}$ & Not specified \\
\hline $\begin{array}{l}\text { Szarpak } \\
\text { et al }{ }^{20}\end{array}$ & 35 & RCT & C & Manikin & $\begin{array}{l}\text { IV and } \\
\text { NIO }\end{array}$ & With PPE & $\begin{array}{l}\text { Paramedics with } \\
\text { a minimum 2-year } \\
\text { experience in } \\
\text { emergency medical } \\
\text { service }\end{array}$ & $\begin{array}{l}\text { From touching } \\
\text { the device to } \\
\text { successful fluid } \\
\text { infusion }\end{array}$ & $\begin{array}{l}\text { Successful } \\
\text { fluid infusion }\end{array}$ \\
\hline
\end{tabular}

Abbreviations: ALS, advanced life support; CP, conference paper; IV, intravenous access; PPE, personal protective equipment; RCT, randomized controlled trial; others, See TABLE 1

by the type of intravascular access devices. Heterogeneity was detected with the $\mathrm{X}^{2}$ test with $\mathrm{n}-1$ degrees of freedom, which was expressed as $I^{2}$. Values of $I^{2}$ greater than $50 \%$ and greater than $75 \%$ were considered to indicate moderate and significant heterogeneity among studies, respectively. ${ }^{13}$ All $P$ values were 2 -tailed and considered significant if less than 0.05 .

Quality assessment of the included studies The methodological quality of the included RCTs was assessed using the "risk of bias" 
tool in accordance with the RevMan software. The following domains were evaluated for RCTs: random sequence generation, allocation concealment, blinding of participants, blinding of outcome assessment, incomplete outcome data, selective reporting, and other bias. ${ }^{12}$ To assess the risk of bias, we only relied on the information presented in the publications. Two researchers (LS and JRL) estimated the risk of bias in each domain as "yes," "no," or "unclear," which reflected a high, low, and uncertain risk of bias, respectively (TABLE 1). The review authors' judgments about each risk of bias item are provided in Supplementary material, Table S2.

RESULTS Study selection The search strategy used in this study produced 947 potential titles and abstracts from database search (FIGURE1). After removing duplicates $(\mathrm{n}=319)$ and screening titles and abstracts, we were left with 34 articles. These were screened against the inclusion and exclusion criteria. A total of 26 articles were excluded, because they represented ineligible study design ( $\mathrm{n}=16)$, were review articles ( $n=4)$, applied ineligible devices $(n=4)$, concerned pediatric population $(n=1)$, and presented duplicate results $(n=1)$. Ultimately, 8 studies that met the inclusion criteria and contained the necessary data for the planned comparison were identified.

Study characteristics The characteristics of the included studies are presented in TABLE 2. Intraosseous access was attempted with the EZ-IO device by 160 operators, ${ }^{8,14-17}$ with a bone injection gun by 60 operators, ${ }^{18,19}$ with the Jamshidi device by 40 operators, ${ }^{18}$ and with the NIO device by 35 operators. ${ }^{20} \mathrm{~A}$ single study was conducted on goats, ${ }^{15}$ another one on turkey femurs, ${ }^{14}$ and others on manikins..$^{8,16-18,20}$ Five articles were original full papers, ${ }^{8,14,16,17,19} 2$ were research letters, ${ }^{18,20}$ and a single one was a conference paper. ${ }^{15}$

Influence of personal protective equipment on intravascular access Seven studies evaluated the duration of an intraosseous access procedure performed with and without PPE., ${ }^{5,14-19}$ The time to complete the procedures was presented in seconds. Obtaining intraosseous access while wearing PPE in comparison with the same procedure without PPE was associated with longer procedure duration (MD, 11.69; 95\% CI, 6.47-16.92; $P<0.001$ ) (FIGURE 2). The intraosseous access success rate with and without PPE was reported in 4 studies ${ }^{14,16,19}$ and was $98.4 \%$ and $99.2 \%$, respectively $(\mathrm{RR}, 1 ; 95 \% \mathrm{CI}$, 0.97-1.03; $P=0.93$ ) (FIGURE 3).

An additional subanalysis by operator's specialty showed that physicians (MD, 10; 95\% CI, 8.42-11.58; $P<0.001$ ), paramedics (MD, 11.46; 95\% CI, 3.62-19.31; $P=0.004)$, as well as a mixed staff group (MD, 15.44; 95\% CI, 11.13-19.75; $P<0.001)$ performed intraosseous access procedures longer when using PPE (TABLE1).

The subanalysis regarding the type of intraosseous device used also revealed shorter time to obtain intraosseous access with EZ-IO (RR, 11.32; 95\% CI, 3.84-18.79; $P=0.003)$, bone injection gun (RR, 9.78; 95\% CI, 8.27-11.29; $P<0.001)$, and Jamshidi (RR, 34.5; 95\% CI, 23.62-45.38; $P<0.001)$ devices as compared with peripheral intravenous access.

Three studies evaluated the time of peripheral intravenous access obtained with and without PPE..$^{8,16,17}$ Intravascular access time with and without PPE was presented in FIGURE 4. The effectiveness of obtaining peripheral intravenous access with and without PPE was reported in 2 studies and equaled $89.9 \%$ versus $100 \%$ (RR, 0.93; 95\% CI, 0.78-1.12; $P=0.44$ ) (FiguRE 5).

Intraosseous and intravenous access procedure duration under personal protective equipment-restricted conditions Five studies presented a comparison of intraosseous and peripheral intravenous accesses performed by an operator wearing PPE. 8,16-18 The overall analysis showed shorter duration of an intraosseous access procedure compared with peripheral intravenous access (MD, $-41.43 ; 95 \% \mathrm{CI},-62.36$ to $-24.47 ; P<0.001$ ) (FIGURE 6 A and $6 \mathrm{~B}$ ).

Subgroup analysis revealed a shorter time to obtain intraosseous access compared with peripheral intravenous access in research letters (MD, -26.3; 95\% CI, -29.57 to -23.03 ; $P<0.001$ ). In original articles, the above finding was not observed (MD, -49.93 ; 95\% CI, -99.86 to 0; $P=0.05)$. Subgroup analysis by operator's profession demonstrated shorter duration of the intraosseous versus peripheral intravenous procedure when performed by paramedics (MD, -21.79; 95\% CI, -29.56 to $-23.04 ; P<0.001)$, as well as by mixed staff (MD, -26.3 ; 95\% CI, -29.56 to -23.04 ; $P=0.008)$ (table 3$)$.

Success rates of intraosseous and intravenous access under personal protective equipment-restricted conditions Three studies reported the success rate of intraosseous versus peripheral intravenous access under PPE-restricted conditions. . $^{8,16,20}$ The efficacy of intraosseous access was $100 \%$ compared with $90.3 \%$ for peripheral intravenous access (RR, 1.08; 95\% CI, 0.97-1.2; $P=0.18$ ) (FIGURE 7A and 7B).

The effectiveness of intravascular access amounted to $100 \%$ for intraosseous compared with $89.9 \%$ for peripheral intravenous access in the subanalysis of original articles (RR, 1.08; 95\% CI, 0.9-1.29; $P=0.44$ ), and to $100 \%$ and $91.4 \%$, respectively, in the subanalysis of research letters (RR, 1.09; 95\% CI, 0.97-1.22; $P=0.13)$. The subanalysis showed that the effectiveness of intraosseous versus peripheral 


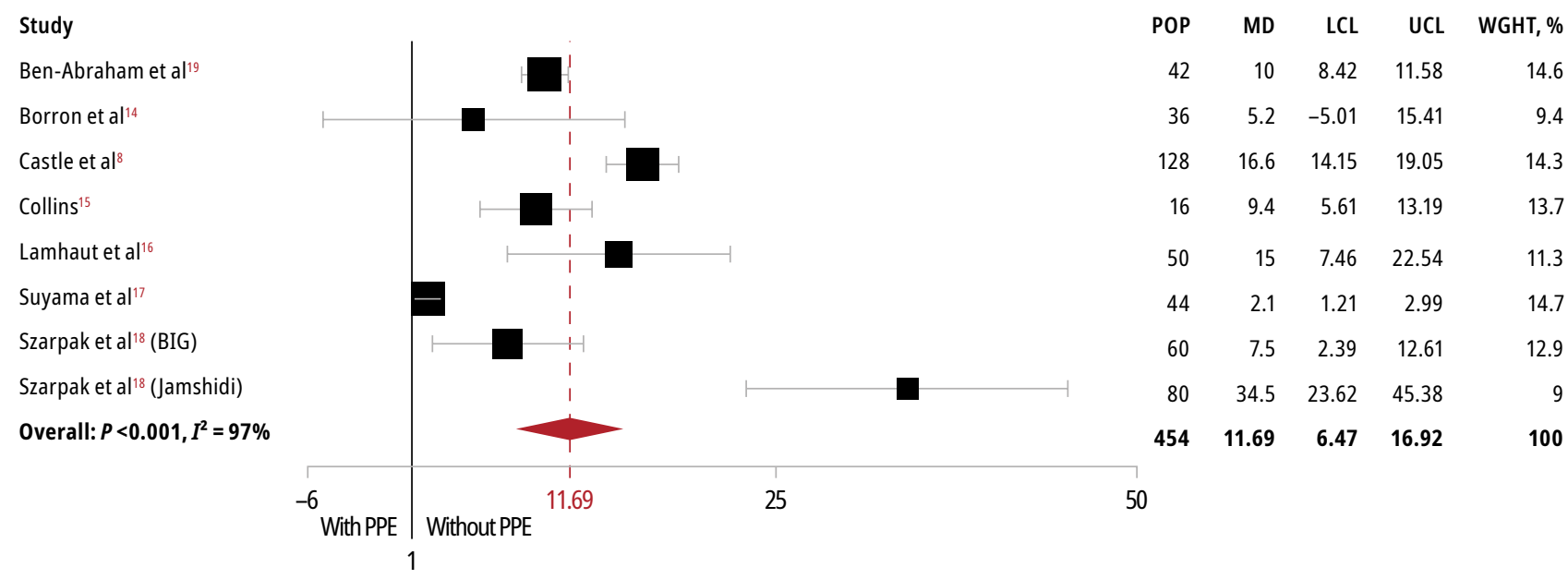

FIGURE 2 Forest plot of intraosseous access procedure duration while using level C personal protective equipment (PPE) versus standard clothing. The center of each square represents the weighted mean difference for individual trials, and the corresponding horizontal line stands for 95\% CI. The diamond represents pooled results. Procedure time was presented in seconds.

Abbreviations: LCL, 95\% lower confidence limit; POP, probability of precipitation; UCL, 95\% upper confidence limit; WGHT, weight; others, see TABLE1

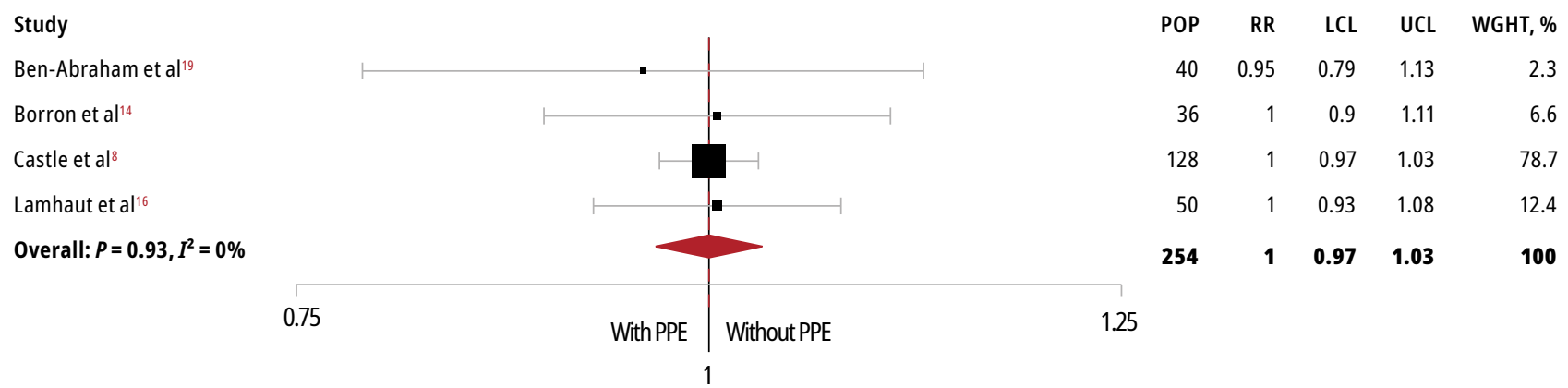

FIGURE 3 Forest plot of intraosseous access success rate while using level C personal protective equipment (PPE) versus standard clothing. The center of each square represents the weighted risk ratio for individual trials, and the corresponding horizontal line stands for $95 \% \mathrm{CI}$. The diamond represents pooled results. Abbreviations: see TABLE 1 and FIGURE 2

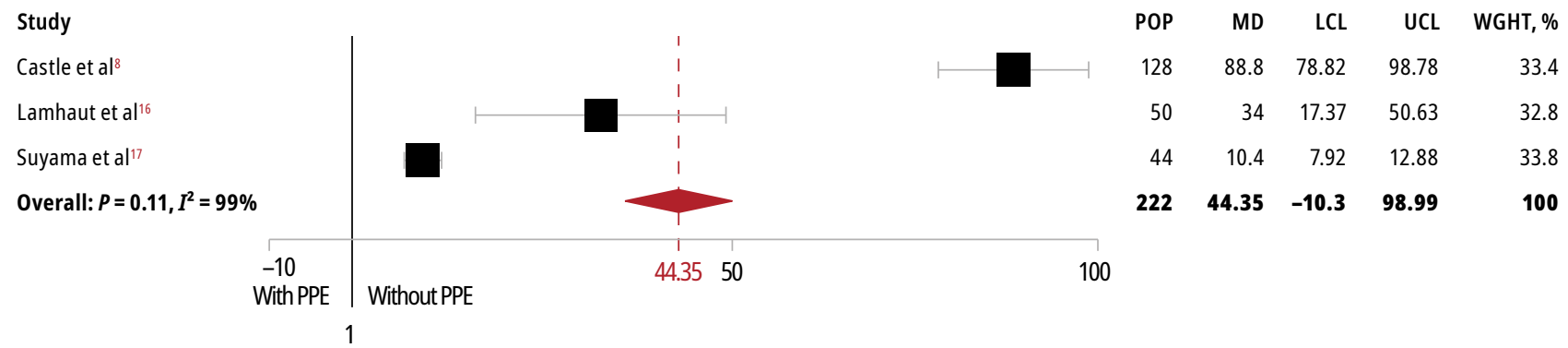

FIGURE 4 Forest plot of peripheral intravenous access procedure duration while using level C personal protective equipment (PPE) versus standard clothing. The center of each square represents the weighted mean difference for individual trials, and the corresponding horizontal line stands for 95\% CI. The diamond represents pooled results. Procedure time was presented in seconds.

Abbreviations: see TABLE 1 and FIGURE 2

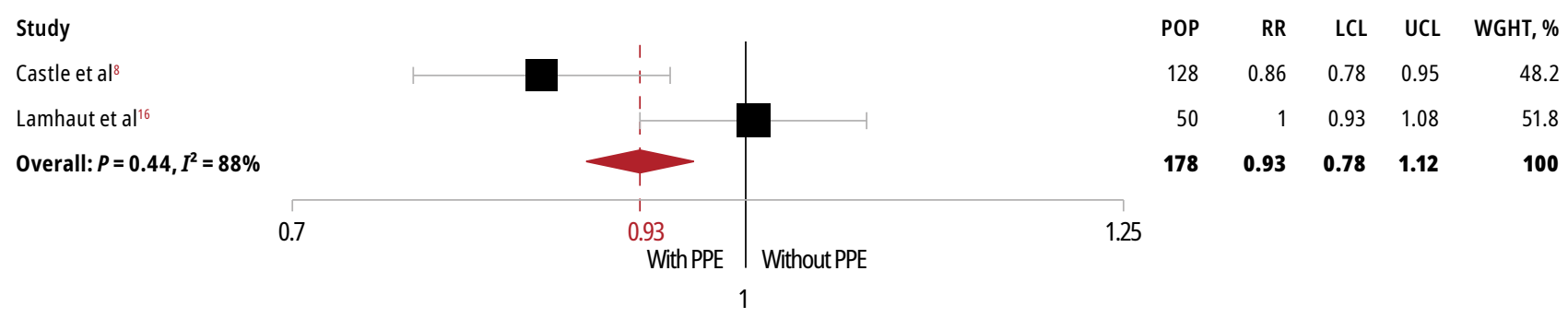

FIGURE 5 Forest plot of peripheral intravenous access success rates while using level C personal protective equipment (PPE) versus standard clothing. The center of each square represents the weighted risk ratio for individual trials, and the corresponding horizontal line stands for $95 \% \mathrm{CI}$. The diamond represents pooled results. Abbreviations: See TABLE 1 and FIGURE2 
A

\begin{tabular}{|c|c|c|c|c|c|c|c|c|}
\hline Study & 1 & & & PO & MD & LCL & UCL & WGHT, \% \\
\hline Castle et $\mathrm{al}^{8}$ & 1 & & & 12 & -93.6 & -103.67 & -83.53 & 24.5 \\
\hline Lamhaut et al'16 & 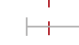 & 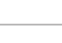 & & 5 & -39 & -52.52 & -25.48 & 23.2 \\
\hline Suyama et al ${ }^{17}$ & $\begin{array}{l}1 \\
1\end{array}$ & & & 4 & -17.5 & -19.34 & -15.66 & 26.2 \\
\hline Overall: $P=0.05, I^{2}=95 \%$ & & & & 22 & -49.93 & -99.86 & 0 & 10 \\
\hline-10 & -49.93 & -30 & -10 & $\begin{array}{c}5 \\
\text { PIV }\end{array}$ & & & & \\
\hline
\end{tabular}

B

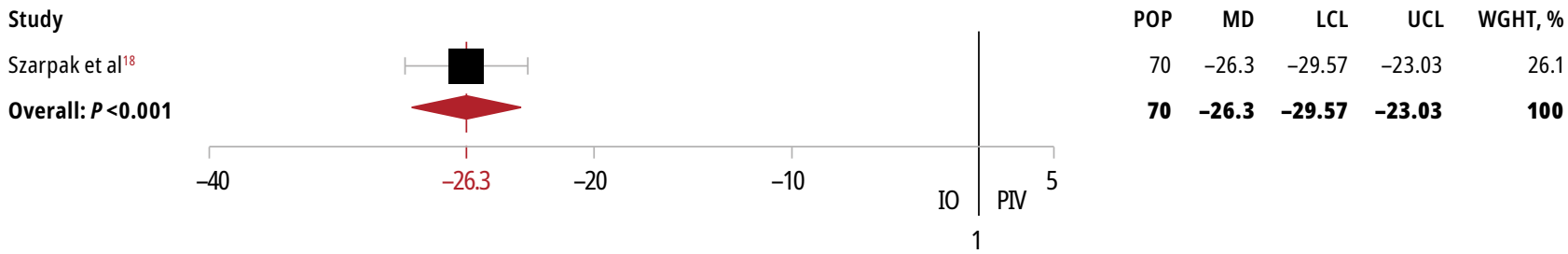

FIGURE 6 Forest plot of intraosseous versus peripheral intravenous access procedure duration while using level C personal protective equipment in original articles $(\mathbf{A})$ and research letters $(\mathbf{B})$. The center of each square represents the weighted mean difference for individual trials, and the corresponding horizontal line stands for $95 \%$ confidence interval. The diamonds represent pooled results.

Abbreviations: See TABLE 1 and FIGURE2

TABLE 3 Comparison of intraosseous and peripheral intravenous access times under personal protective equipment-restricted conditions

\begin{tabular}{|c|c|c|c|c|c|c|c|}
\hline Variable & & Trials, $\mathrm{n}$ & I0 efficacy, \% & PIV efficacy, \% & RR or MD $(95 \% \mathrm{CI})$ & $P$ value & $I^{2}$ statistics, $\%$ \\
\hline \multirow{2}{*}{$\begin{array}{l}\text { Procedure } \\
\text { duration }\end{array}$} & Paramedics & 2 & NA & NA & $-21.79(-29.56$ to -23.04$)$ & $<0.001$ & 95 \\
\hline & Mixed staff & 3 & NA & NA & $-26.3(-29.56$ to -23.04$)$ & 0.008 & 97 \\
\hline \multirow[t]{2}{*}{ Success rate } & Paramedics & 1 & 100 & 91.4 & $1.09(0.97-1.22)$ & 0.13 & NA \\
\hline & Mixed staff & 3 & 100 & 89.9 & $1.09(0.9-1.29)$ & 0.44 & 88 \\
\hline
\end{tabular}

Abbreviations: IO, intraosseous access; PIV, peripheral intravenous access; others, see TABLE 1

A

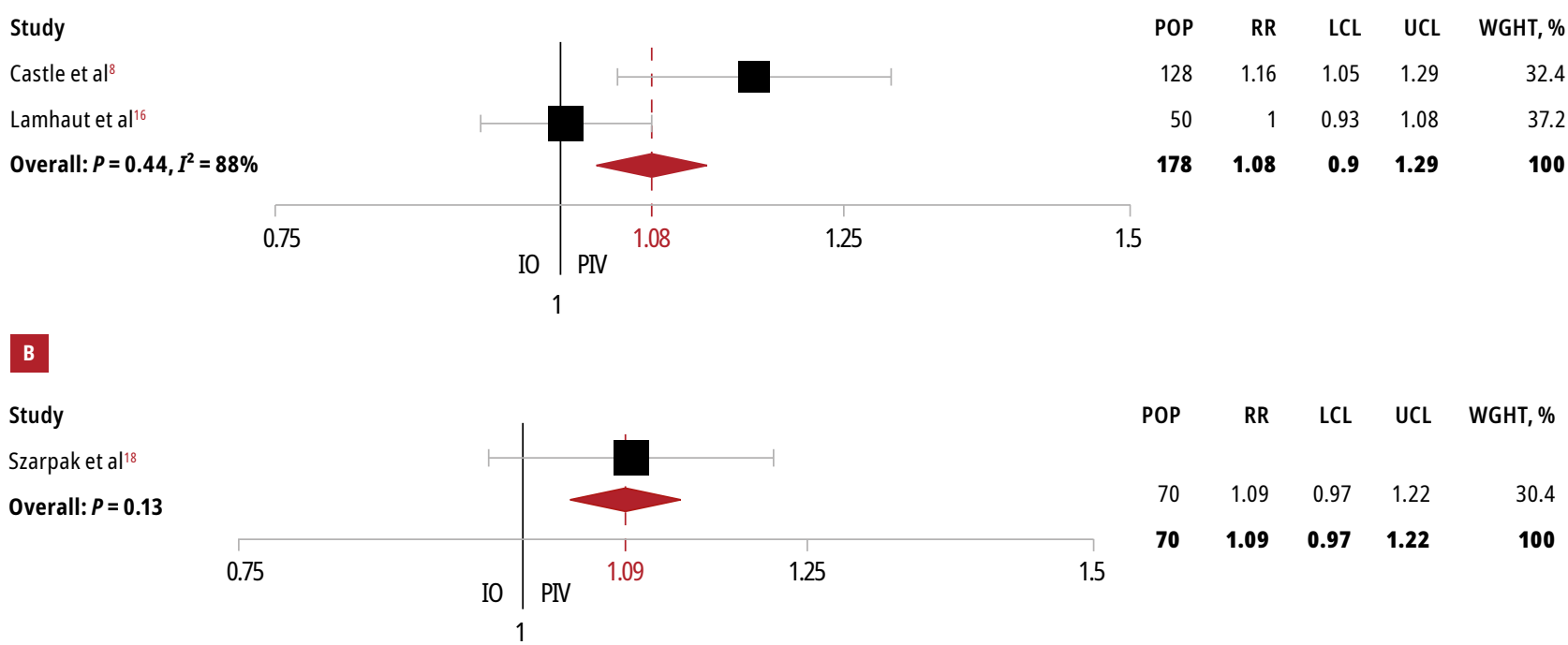

FIGURE 7 Forest plot of intraosseous versus peripheral intravenous access success rates while using level C personal protective equipment in original articles (A) and research letters (B). The center of each square represents the weighted risk ratio for individual trials, and the corresponding horizontal line stands for $95 \%$ CI. The diamonds represent pooled results.

Abbreviations: See FIGURE 2 and TABLE 3 
intravenous access varied and amounted to $100 \%$ and $91.4 \%$, respectively, in the paramedics group (RR, 1.09; 95\% CI, 0.97-1.22; $P=0.13$ ) and to $100 \%$ and $89.9 \%$, respectively, among mixed staff (RR, 1.09; 95\% CI, 0.9-1.29; $P=0.44$ ) (TABLE3).

Risk of bias in the included trials The risk of bias in the included studies is outlined in TABLES1 and 2. All the 8 studies clearly described random sequence generation..$^{8,14-20}$ The risk of bias in the RCTs was assessed as either low or moderate across all domains, apart from the blinding of participants and personnel, where blinding was clearly not possible.

DISCUSSION Quick intravascular access is the key to the successful management of patients with shock, trauma, or cardiac arrest. The major finding of this meta-analysis is that when an operator is wearing level C PPE, intraosseous access offers advantages over peripheral intravenous access in terms of procedure duration and success rates. Moreover, the use of PPE increases the duration and significantly reduces the effectiveness of peripheral intravenous access. In the case of intraosseous access, the use of PPE increases the duration of the procedure, however, the effectiveness decreases by only $0.8 \%$ compared with the procedure performed without a protective suit.

The conducted meta-analysis showed a significantly shorter time of obtaining intraosseous access in comparison with peripheral intravenous access, as well as an advantage regarding the effectiveness of intraosseous over peripheral intravenous access. The American Heart Association indicates in its guidelines for advanced resuscitation that it is reasonable to establish intraosseous access if intravenous access is not readily available. ${ }^{21}$ However, extraordinary situations (including caring for patients with suspected or confirmed COVID-19, when medics are wearing level C PPE) require extraordinary measures. Consequently, a different vascular access technique may be advised to increase patient safety, at least as a bridging procedure during ongoing resuscitation efforts, until the patient is in a more stable condition. It would therefore be appropriate to prioritize obtaining intraosseous access when using PPE suits.

The use of full level C PPE undoubtedly affects the quality of the performed procedures by making movement difficult. Additionally, applying double gloves during procedures is more protective than using a single pair as far as percutaneous needle injuries during intravenous cannulation are considered, ${ }^{22,23}$ especially in the case of highly infectious patients. At the same time, this practice impairs comfort, sensitivity, and dexterity ${ }^{24}$ reducing the effectiveness and increasing the duration of numerous medical procedures. ${ }^{8}$ However, owing to the increased protective effect against needle-stick injuries, double gloves should be used routinely in contact with infected patients.

As indicated by Iskrzycki et al, ${ }^{25}$ the risk of potential complications is one of the main concerns about the use of intraosseous access among physicians. Complications of intraosseous access were reported as rare and mostly minor. ${ }^{26,27}$ Their majority occurs when aseptic and antiseptic rules are not followed, as well as when intraosseous access is kept too long. ${ }^{28}$ The most significant issue for conscious patients with an intraosseous device in situ was their experience of pain. Ong et $\mathrm{al}^{29}$ recommended the administration of 20 to $50 \mathrm{mg}$ of $2 \%$ lidocaine to all conscious patients, although the effectiveness of this strategy has not been evaluated.

Another factor in favor of the routine use of intraosseous access in suspected or confirmed COVID-19 patients with cardiovascular and/or respiratory failure is that most drugs can be administered via intraosseous access in equivalent dosage and with the same time effect compared with peripheral intravenous access. The pharmacodynamics and pharmacokinetic effects of intraosseously applied drugs and infusions are well described in the literature..$^{30-32}$

Alternative vascular access techniques in adult patients undergoing resuscitation with impossible peripheral intravenous catheterization include central venous catheterization or ultrasound-guided catheterization of peripheral veins. The presented analysis did not include studies on the comparison of intraosseous versus central venous catheterization, as the latter should not be used as the primary method of obtaining vascular access under emergency medicine conditions, especially in patients with cardiovascular and / or respiratory failure. As shown by Leidel et al, ${ }^{33}$ in the emergency department, in adults undergoing cardiopulmonary resuscitation with inaccessible peripheral veins, the efficacy of the first attempt to obtain vascular access with the intraosseous method equaled $85 \%$ and was higher than the $60 \%$ for central venous catheterization $(P$ $=0.024$ ). In addition, the procedure for obtaining central access should be carried out under ultrasound guidance ${ }^{34,35}$ and is relatively time-consuming and associated with relevant risks for the patient, especially in the emergency setting. Furthermore, central venous catheterization or ultrasound-guided catheterization of peripheral veins require the ultrasound device and an experienced operator and are more time-consuming compared with obtaining intraosseous or peripheral intravenous access. ${ }^{36}$

Current Infection and Control recommendations for Healthcare Personnel endorsed by Centers for Disease Control and Prevention suggest that all healthcare personnel working in healthcare facilities should wear a facemask at all times. 
If working in facilities located $\mathrm{n}$ the region of moderate-to-substantial community transmission, healthcare personnel should additionally wear eye protection. If performing any aerosol-generating or surgical procedures, an N95 or higher-level respirator, gloves, and a gown should be used.

Limitations As a limitation, all of the included studies in our meta-analysis were small in size and were at high risk of bias, because neither the operator nor the outcome assessor were blinded for obvious technical reasons. We found a significant heterogeneity regarding procedure duration, as well as procedure success rates, most likely secondary to the varied experience levels of study participants. As the number of studies was small, it was not possible to conduct a meta-regression analysis to identify potential causes of heterogeneity. Another limitation is that all research was experimental and was not carried out on humans, but it is difficult and sometimes even impossible to do such research in a group of highly infectious patients, as it would potentially delay the therapeutic procedure. We focused on level C PPE in this meta-analysis, because this might be most commonly used in emergency medicine, but the level of PPE used in the included studies might vary. While the level of PPE is standardized in the United States, it might differ among various hospitals and healthcare settings around the globe.

Conclusions This comprehensive meta-analysis suggests that the use of PPE significantly extends the duration of intravascular access procedures. Moreover, it was observed that, under PPE-restricted conditions, operators were able to obtain intraosseous access in a shorter time and with a higher success rate compared with peripheral intravenous access. As the overall quality of evidence is universally low and limited to experimental, mostly simulation, trials, an RCT of human patients is warranted.

\section{SUPPLEMENTARY MATERIAL}

Supplementary material is available at www.mp.pl/kardiologiapolska.

\section{ARTICLE INFORMATION}

ACKNOWLEDGMENTS This study was supported by the ERC Research NET and the Polish Society of Disaster Medicine.

CONTRIBUTION STATEMENT All authors confirm that they had full access to data, contributed to drafting the paper, analyzed the data, edited the paper, and approved the final version of the manuscript. $A D$ and $t S$ designed and coordinated the study.

\section{CONFLICT OF INTEREST None declared.}

OPEN ACCESS This is an Open Access article distributed under the terms of the Creative Commons Attribution-NonCommercial-NoDerivatives $4.0 \mathrm{In}$ ternational License (CC BY-NC-ND 4.0), allowing third parties to download articles and share them with others, provided the original work is properly cited, not changed in any way, distributed under the same license, and used for noncommercial purposes only. For commercial use, please contact the journal office at kardiologiapolska@ptkardio.pl.

HOW TO CITE Drozd A, Smereka J, Filipiak KJ, et al. Intraosseous versus intravenous access while wearing personal protective equipment: a meta-analysis in the era of COVID-19. Kardiol Pol. 2021; 79: 277-286. doi:10.33963/KP.15741

\section{REFERENCES}

1 Burgert JM. Intraosseous vascular access in disasters and mass casualty events: a review of the literature. Am J Disaster Med. 2016; 11: 149-166.

2 Franklin SM. A comparison of personal protective standards: caring for patients with Ebola virus. Clin Nurse Spec. 2016; 30: E1-E8.

3 Beam EL, Schwedhelm S, Boulter K, et al. Personal protective equipment processes and rationale for the Nebraska Biocontainment Unit during the 2014 activations for Ebola virus disease. Am J Infect Control. 2016; 44: 340-342.

4 Zhou F, Yu T, Du R, et al. Clinical course and risk factors for mortality of adult inpatients with COVID-19 in Wuhan, China: a retrospective cohort study. Lancet. 2020; 395: 1054-1062.

5 Smereka J, Szarpak L. The use of personal protective equipment in the COVID-19 pandemic era. Am J Emerg Med. 2020; 38: 1529-1530.

6 Wu Z, McGoogan JM. Characteristics of and important lessons from the coronavirus disease 2019 (COVID-19) outbreak in China: summary of a report of 72314 cases from the Chinese Center for Disease Control and Prevention. JAMA. 2020; 323: $1239-1242$.

7 Smereka J, Ruetzler K, Szarpak L, et al. Role of mask/respirator protection against SARS-CoV-2. Anesth Analg. 2020; 131: e33-e34.

8 Castle N, Owen R, Hann M, et al. Impact of chemical, biological, radiation, and nuclear personal protective equipment on the performance of low- and high-dexterity airway and vascular access skills. Resuscitation. 2009; 80: 1290-1295.

9 Clemency B, Tanaka K, May P, et al. Intravenous vs. intraosseous access and return of spontaneous circulation during out of hospital cardiac arrest. Am J Emerg Med. 2017; 35: 222-226.

10 Smereka J, Szarpak L, Filipiak KJ, Jaguszewski M. Which intravascular access should we use in patients with suspected/confirmed COVID-19? Resuscitation. 2020; 151: 8-9.

11 Moher D, Shamseer L, Clarke M, et al. Preferred reporting items for systematic review and meta-analysis protocols (PRISMA-P) 2015 statement. Syst Rev. 2015; 4: 1-9.

12 Higgins JP, Altman DG, Gøtzsche PC, et al. The Cochrane Collaboration's tool for assessing risk of bias in randomised trials. BMJ. 2011; 11: 343-351.

13 Hozo SP, Djulbegovic B, Hozo I. Estimating the mean and variance from the median, range, and the size of a sample. BMC Med Res Methodol. 2005; 5 ; 1-10.

14 Borron SW, Arias JC, Bauer CR, et al. Intraosseous line placement for antidote injection by first responders and receivers wearing personal protective equipment Am J Emerg Med. 2011; 29: 373-381.

15 Collins CM. Vascular access: a military perspective. Br J Nurs. 2017; 26 : S39-S39.

16 Lamhaut L, Dagron C, Apriotesei R, et al. Comparison of intravenous and intraosseous access by pre-hospital medical emergency personnel with and without CBRN protective equipment. Resuscitation. 2010; 81: 65-68.

17 Suyama J, Knutsen CC, Northington WE, et al. IO versus IV access while wearing personal protective equipment in a HazMat scenario. Prehosp Emerg Care. 2007; 11: 467-472.

18 Szarpak L, Ramirez JG, Buljan D, et al. Comparison of Bone Injection Gun and Jamshidi intraosseous access devices by paramedics with and without chemical-biological-radiological-nuclear personal protective equipment: a randomized, crossover, manikin trial. Am J Emerg Med. 2016; 34: 1307-1308.

19 Ben-Abraham R, Gur I, Vater Y, Weinbroum AA. Intraosseous emergency access by physicians wearing full protective gear. Acad Emerg Med. 2003; 10: 1407-1410.

20 Szarpak L, Truszewski Z, Smereka J, et al. Comparison of two intravascular access techniques when using CBRN-PPE:a randomized crossover manikin trial. Am J Emerg Med. 2016; 34: 1170-1172.

21 Link MS, Berkow LC, Kudenchuk PJ, et al. Part 7: adult advanced cardiovascular life support: 2015 American Heart Association Guidelines update for cardiopulmonary resuscitation and emergency cardiovascular care. Circulation. 2015; 132: S444-S464.

22 Din SU, Tidley MG. Needlestick fluid transmission through surgical gloves of the same thickness. Occup Med. 2014; 64: 39-44.

23 Szarpak $Ł$, Kurowski A. Do double gloves protect against contamination during cannulation of blood vessels? A prospective randomized study. Med Pr. 2014; 65: 271-278.

24 Wilson SJ, Sellu D, Uy A, et al. Subjective effects of double gloves on surgical performance. Ann R Coll Surg Engl. 1996; 78: 20-22.

25 Iskrzycki L, Smereka J, Szarpak L. Knowledge, skills, and attitudes concerning intraosseous access among hospital physicians. Crit Care Med. 2017; 45: e117.

26 Whitney R, Langhan M. Vascular access in pediatric patients in the emergency department: types of access, indications, and complications. Pediatr Emerg Med Pract. 2017; 14: 1-20.

27 Johnson M, Inaba K, Byerly S, et al. Intraosseous infusion as a bridge to definitive access. Am Surg. 2016; 82: 876-880.

28 Petitpas F, Guenezan J, Vendeuvre T, et al. Use of intra-osseous access in adults: a systematic review. Crit Care. 2016; 20: 1-9.

29 Ong ME, Chan YH, Oh J], et al. An observational, prospective study comparing tibial and humeral intraosseous access using the EZ-IO. Am J Emerg Med. 2009; 27: 8-15. 
30 Burgert J, Gegel B, Loughren M, et al. Comparison of tibial intraosseous, sternal intraosseous, and intravenous routes of administration on pharmacokinetics of epinephrine during cardiac arrest: a pilot study. AANA J. 2012; 80: S6-S10.

31 Hoskins SL, do Nascimento P Jr, Lima RM, et al. Pharmacokinetics of intraosseous and central venous drug delivery during cardiopulmonary resuscitation. Resuscitation. 2012; 83: 107-112.

32 Johnson D, Giles K, Acuna A, et al. Effects of tibial intraosseous and IV administration of vasopressin on kinetics and survivability in cardiac arrest. Am J Emerg Med. 2016; 34: 429-432.

33 Leidel BA, Kirchhoff C, Bogner V, et al. Comparison of intraosseous versus central venous vascular access in adults under resuscitation in the emergency department with inaccessible peripheral veins. Resuscitation. 2012; 83: 40-45.

34 Ablordeppey EA, Drewry AM, Beyer AB, et al. Diagnostic accuracy of central venous catheter confirmation by bedside ultrasound versus chest radiography in critically ill patients: a systematic review and meta-analysis. Crit Care Med. 2017; 45: 715-724.

35 Simon EM, Summers SM. Vascular access complications: an emergency medicine approach. Emerg Med Clin North Am. 2017; 35: 771-788.

36 Mills CN, Liebmann 0 , Stone MB, et al. Ultrasonographically guided insertion of a 15-cm catheter into the deep brachial or basilic vein in patients with difficult intravenous access. Ann Emerg Med. 2007; 50: 68-72. 